Edited by:

Hubert Vaudry, University of Rouen,

France

Reviewed by:

Hubert Vaudry, University of Rouen, France

Arnold De Loof, University of Leuven, Belgium

*Correspondence:

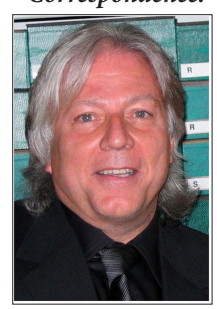

Dick R. Nässel obtained his PhD in Zoology from Lund University, Lund, Sweden in 1977. He had a postdoctoral scholarship and then a staff position at European Molecular Biology Laboratory $(E M B L)$ in Heidelberg, Germany in 1978-1981. After 6 years as an associate professor at Lund University, he was employed as a full professor at Stockholm University in 1988. His research has over the last 25 years focused on modulatory roles of neuropeptides in the insect nervous system. The last dozen years, his research group has worked on Drosophila neuropeptides and peptide hormones, and more recently on insulin signaling. dnassel@zoologi.su.se

\section{Cholecystokinin-like peptide (DSK) in Drosophila, not only for satiety signaling}

\author{
Dick R. Nässel ${ }^{1 *}$ and Michael J. Williams² \\ 1 Department of Zoology, Stockholm University, Stockholm, Sweden \\ 2 Functional Pharmacology, Department of Neuroscience, Uppsala University, Uppsala, Sweden
}

Cholecystokinin (CCK) signaling appears well conserved over evolution. In Drosophila, the CCK-like sulfakinins (DSKs) regulate aspects of gut function, satiety and food ingestion, hyperactivity and aggression, as well as escape-related locomotion and synaptic plasticity during neuromuscular junction development. Activity in the DSK-producing neurons is regulated by octopamine. We discuss mechanisms behind CCK function in satiety, aggression, and locomotion in some detail and highlight similarities to mammalian CCK signaling.

Keywords: neuropeptide, peptide hormone, aggression, feeding, intestinal function, locomotion

\section{INTRODUCTION}

Many neuropeptide signaling pathways are well conserved over evolution (1-3). One example is the cholecystokinin (CCK) signaling that regulates satiety and food intake in nematode worms, insects, and mammals (4-8). The first CCK-like peptide of insects was isolated from the cockroach, Leucophaea maderae, and designated leucosulfakinin (9). In Drosophila, two sulfakinins (DSK1 and DSK2; encoded by CG18090) and two DSK receptors (CCKLR1 and CCKLR2; encoded by CG6881 and CG6857) have been identified (10-12). The DSKs display strong sequence similarities to vertebrate gastrin/CCKs and sulfakinins (SKs) of other invertebrates (Table 1) and also their G-protein coupled receptors (GPCRs) are well conserved, suggesting a ligand-receptor coevolution (13). Actually, the amino acid sequences of the two DSKs are identical in the nine residues of the carboxy terminus, and DSK-II is N-terminally extended by five residues compared to DSK-I (12) (Table 1). The tyrosine residues of mammalian CCK, and many of the insect sulfakinins, are sulfated, a modification essential for proper activation of their receptors.

In mammals, CCK secreted from the intestine acts on receptors in the nucleus of the solitary tract of the brain to signal satiety and thus inhibit feeding $(7,14)$. In Drosophila, DSKs released from insulin-producing cells (IPCs) of the brain appear sufficient to induce satiety $(8,15)$. As with many neuropeptides and peptide hormones, CCK is multifunctional and can also act locally in the intestine to decrease gastrointestinal motility, stimulate secretion of pepsinogen, inhibit gastric

\section{KEY CONCEPT 1 | Neuropeptides and peptide hormones}

Neuropeptides and peptide hormones typically consist of 5-80 amino acids linked by peptide bonds. They act on G-protein-coupled receptors (GPCRs) or in some cases receptor tyrosine kinases. In Drosophila, about 50 genes have been identified that encode precursors of neuropeptides or peptide hormones, and more than 45 GPCRs are known.

acid secretion, stimulate gallbladder contraction, and trigger secretion of hormones in the pancreas $(13,16)$. Furthermore, CCK released from brain neuroendocrine cells has regulatory functions in nociception, memory and learning processes, panic, and anxiety (17). To what extent are these 
Table 1 | Sequences of CCK-like peptides ${ }^{a}$.

\begin{tabular}{lll}
\hline DSK-I & Drosophila melanogaster & FDDYGHMRFamide \\
DSK-II & Drosophila melanogaster & GGDDOFDDYGHMRFamide \\
DSK 0 & Drosophila melanogaster & NQKTMSFamide \\
LSK & Leucophaea maderae & pQSDDYSGHMRFamide \\
CCK-1 & Aplysia californica & SYGDYGIGGGRFamide \\
CCK-2 & Aplysia californica & QGAWSYDYGLGGGRFamide \\
NPL-12a & Caenorhabditis elegans & DYRPLQFamide \\
NPL-12b & Caenorhabditis elegans & DGYRPLQFamide \\
CCK8 & Mammals & DYMGWMDFamide \\
\hline
\end{tabular}

${ }^{a}$ Sequences from Ref. $(2,6,9$, 12). Bold tyrosine (Y) residues are sulfated.

\section{KEY CONCEPT 2 | Neuroendocrine cells}

Neuropeptides and peptide hormones are produced by a variety of neurons, and neuroendocrine cells in the central and peripheral nervous system as well as in glandular cells in other tissues, including the intestinal tract. Within the CNS, peptidergic neurons form a large variety of modulatory circuits. Peptide hormones are typically released into the circulation.

CCK functions subserved by DSKs in Drosophila and SKs of other insects? We provide a brief update on DSK signaling in Drosophila and show that, in addition to inducing satiety, several functions are conserved over evolution.

\section{MULTIPLE ROLES OF SULFAKININS IN INTESTINAL FUNCTION IN INSECTS}

In several insects, it was shown that SKs modulate spontaneous activity of the foregut and hindgut muscle, as well as heart contractions [see Ref. $(3,9,13,18)]$. In some insect species, SKs were also shown to induce secretion of the digestive enzyme $\alpha$-amylase (19). In Drosophila, the enteroendocrine cells of the gut do not produce DSKs, and there is no direct innervation of the posterior intestine by DSK-expressing neurons $(20,21)$. Thus, actions of DSKs on the more posterior intestine are likely to be hormonal, via release from median neurosecretory cells (MNCs) that also produce insulin-like peptides and have axon terminations in neurohemal regions of the

\section{KEY CONCEPT 3 | Median neurosecretory cells}

In insects, a region in the dorsal midline of the brain, designated pars intercerebralis, contains a group of median neurosecretory cells (MNCs) that produce a number of peptide hormones, including insulin-like peptides (DILPS) and CCK-like peptides (DSKs). This brain region is considered functionally analogous to the hypothalamus.

corpora cardiaca and anterior aorta, crop duct, and anterior midgut $(8,22)$. The DSK action on the heart, crop, and anterior intestine could, however, be by means of direct release onto these structures by axon terminations of the same neurosecretory cells. Taken together, these findings indicate that insect SKs and mammalian CCKs have some conserved actions in relation to intestinal function.

\section{SATIETY SIGNALING}

Endocrinological studies demonstrated that SKs inhibit food intake in several insects, such as blowfly, locust, cricket, cockroach, and the beetle Tribolium castaneum (5, 13, 23-26). In Drosophila, targeted genetic interference with expression of DSKs also revealed that these peptides are important for satiety signaling $(8,15)$. In the adult Drosophila CNS, there is a small number of DSK-

\section{KEY CONCEPT 4 | Satiety signaling}

Hunger and satiety can be determined either by willingness to approach food, or by amount of food ingested. Food intake in adult Drosophila can be monitored by a capillary feeding (CAFE) assay: flies feed from a calibrated capillary, and the amount ingested is calculated from the diminished level in the capillary. In some cases colored food is used and ingestion is determined by spectrophotometry.

producing neurons: four very large interneurons posteriorly in the brain, about eight smaller interneurons dorsolaterally and ventrally in the brain, and a varying number of MNCs $(8,20)$. The DSKexpressing MNCs are a subpopulation of the 14 IPCs (8). Thus, most of the IPCs produce both the insulin-like peptides DILP2, 3 , and 5 and the DSKs.

Knockdown of DSK by RNAi targeted to DSK-producing neurons decreased satiety signaling in flies and hence intake of food increased, even when it was less palatable with no sugar or bitter with caffeine added (8). It was furthermore shown that knockdown of DSK only in the IPCs was sufficient to produce the same phenotype, suggesting that the hormonal action of DSKs is important as a satiety signal. Similar results were obtained from third instar larvae. In flies, inactivation of the IPCs or all the DSK-producing neurons by targeted expression of a hyperpolarizing potassium channel (Ork1) generated the same phenotype on food intake, indicating that activity in the IPCs is required to induce satiety (8). Flies deficient in DSKs displayed increased resistance to starvation compared to control flies, probably as a consequence of the dysregulated satiety signaling and resulting increase in food intake (8). Interestingly, knocking down DSKs either in IPCs or in all DSK-producing cells led to compensatory increases of Dilp2, 3, and 5 transcripts in the brain of flies fed ad libitum, but had no effect on flies starved for $24 \mathrm{~h}$. Another study revealed that the Drosophila obesity-linked homologs Transcription factor AP-2 (TfAP-2) and Tiwaz (Twz) regulate octopamine signaling to initiate feeding and then octopamine, in a negative feedback loop, induces expression of Dsk to inhibit consummatory behavior (15). Combined, these findings suggest that DSKs released from IPCs are sufficient to induce satiety in larval and adult Drosophila, but the mechanisms remain elusive. The DSK receptor localization and targets of the peptide are yet to be identified, and it remains possible that the action could be either central or peripheral.

There are several sets of neurons in the brain known to regulate feeding. Among these are the so-called hugin neurons that produce a neuropeptide of pyrokinin type, whose branches are known to superimpose those of the IPCs (27). Functional interactions between the brain IPCs and the hugin neurons were demonstrated recently (28). The IPCs could signal to the hugin neurons by both DILPs and DSKs and thereby regulate the activity in these neurons that are at the interface between gustatory inputs and feeding regulation. There are several other candidate targets among central neurons. Neurons in circuits that use the following neurotransmitters and neuropeptides have been implicated in the regulation of foraging and feeding in addition to DILPs and DSKs: dopamine 
(DA), neuropeptide F, short neuropeptide F, allatostatin A, leucokinin, and hugin [see Ref. $(3,29)]$. These sets of neurons are shown schematically in Figure 1.

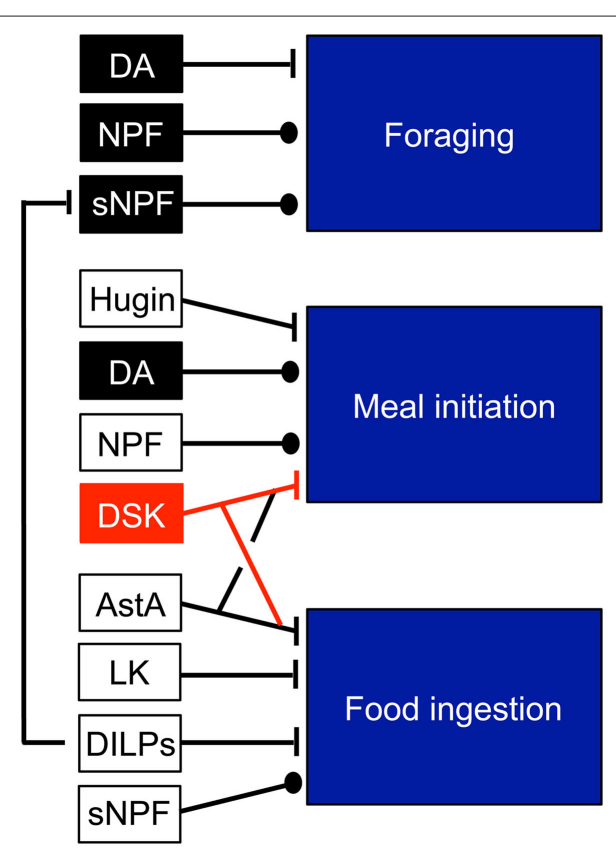

FIGURE 1 | Neuromodulators that regulate feeding modules in Drosophila. The neuromodulators in black and red units are produced by identified neurons: dopamine (DA) in DL1 neurons (for foraging) and in ventral unpaired neurons (for meal initiation), NPF in non-clock NPF neurons, sNPF in olfactory sensory neurons (OSNs), DSK in IPCs. The other peptides Hugin, allatostatin $A(A s t A)$, leucokinin (LK) are produced by several neurons types and it is not known which mediate the feeding responses. Probably, DILPs from IPCs contribute to inhibition of food ingestion. Note that DILPs inhibit the sNPF signaling in OSNs. This figure was compiled from data in Figure 3 in Ref. (29).

\section{AGGRESSION AND ANXIETY}

It was demonstrated that CCK signaling through the CCK B receptor (CCKBR) within the rodent brain induces hyperactivity and aggression $(30,31)$. In support of this, CCKergic neuronal projections were identified within the limbic system, the brainstem, and the cerebral cortex, many of which overlap with neuronal pathways considered to be significant for the modulation of fear, anxiety, and aggression [for review, see Ref. (32)]. Furthermore, overexpression of CCKBR in the mouse brain increased aggressive behavior, while mice lacking CCKBR displayed increased exploratory behavior and reduced anxiety $(31,33)$.

In Drosophila, while DA and serotonin are involved in the modulation of aggressive behavior, the central regulator of aggression is the noradrenaline analog, octopamine (34-37). Recently, it was

\section{KEY CONCEPT 5 | Aggressive behavior}

Male fruitflies fight over mates and resources and display elaborate aggressive behavior. The neuronal circuitry regulating aggressive behavior in Drosophila is intensely studied with genetic methods. Both monoamines and neuropeptides are known modulators of aggression in flies. It has been possible to identify small groups of neurons that regulate specific aspects of aggression.

reported that Drosophila homologs of the human obesity-linked genes TFAP2B and KCTD15 [TfAP-2 and Tiwaz (Twz)] regulate at least two genes involved in the production and secretion of octopamine within the brain, Tyramine $\beta$ hydroxylase (Tbh) and Vesicular monoamine transporter (Vmat) (Figure 2). Octopamine then regulates aggression, mating, and activity in Drosophila by controlling the expression of Dsk in the IPCs (36) (Figure 2).

Overexpressing TfAP-2 in octopaminergic neurons was sufficient to induce the expression of Dsk. This Dsk induction was blocked by feeding males an octopamine antagonist, indicating that TfAP-2 and Twz induce Dsk expression via octopamine signaling (Figure 2). Furthermore, Dsk overexpression in the IPCs was itself sufficient to induce hyperactivity and aggressive behavior. Interestingly, TfAP-2-induced aggressive behavior was

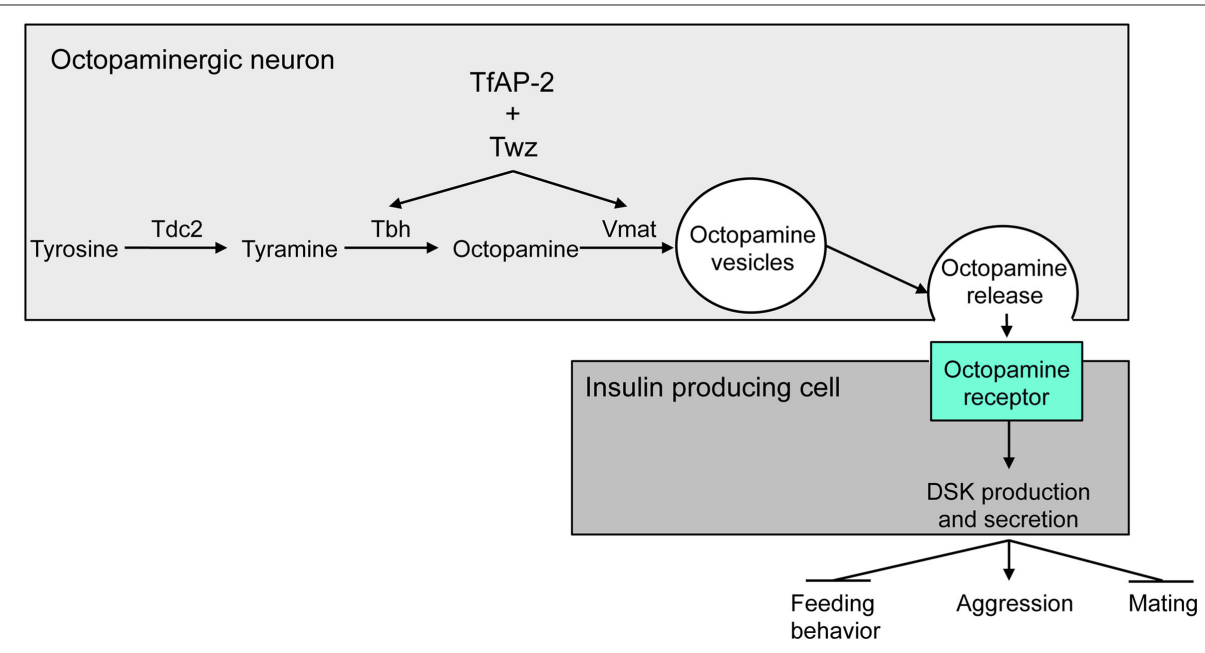

FIGURE 2 | Model for the regulation of aggressive behavior by DSK. TWZ and TfAP-2 regulate the expression of Tbh and Vmat, which control octopamine production and release from octopaminergic neurons. Octopamine then signals to the IPCs to induce Dsk transcription. Dsk signals to stimulate aggression, while inhibiting mating and feeding behavior (15). This figure was modified from Figure 8 in Ref. (36). 
blocked by feeding flies, a CCK antagonist. This suggests that octopamine-induced aggression is due to an increase in DSK signaling (Figure 2).

\section{DEVELOPMENT OF THE NEUROMUSCULAR JUNCTION AND MODULATION OF LOCOMOTION}

Similar to mammals, the Drosophila genome encodes two different Dsk receptors, CCKLR1 (CCKLR-17D1) and CCKLR2 (CCKLR17D3). In Drosophila larvae, CCKLR-17D1 signaling was reported to be necessary for body-wall muscle contractions involved in stress-induced escape behavior (38). Moreover, it was demonstrated that Dsk and CCKLR-17D1 are required for proper neuromuscular junction (NMJ) formation in larvae (39). Interestingly, another study reported that octopamine regulates synaptic plasticity in the NMJ during development, as well as under starvation conditions. By activating Oct $\beta 2 \mathrm{R}$ receptors in octopaminergic neurons, octopamine initiates signaling events that induce the development of new synaptic boutons at larval NMJs $(40,41)$. This lends itself to the hypothesis that, similar to what was reported in the Drosophila brain, octopamine and Dskinteract at NMJs to regulate their development, as well as plasticity under condition of increased locomotor behavior.

\section{CONCLUSION AND OUTLOOK}

The CCK-like peptides, DSKs, of Drosophila and SKs of other insects regulate gut function, satiety/food ingestion, hyperactivity, and aggression, as well as escape-related locomotion and synaptic plasticity during NMJ development. Thus, many of the functional roles of CCK signaling known in mammals are present also in insects. Recent studies have shown that the neurons producing DSKs are under regulatory control by octopaminergic neurons (36) and more specifically the IPCs that co-express DILPs and DSKs are regulated by the octopamine receptor OAMB (42). An important question for the future is to determine the targets of DSK signaling within the brain and at peripheral sites that regulate the different aspects of behavior and physiology.

\section{REFERENCES}

1. Jekely G. Global view of the evolution and diversity of metazoan neuropeptide signaling. Proc Natl Acad Sci U S A (2013) 110(21):8702-7. doi: 10.1073/ pnas. 1221833110

2. Mirabeau O, Joly JS. Molecular evolution of peptidergic signaling systems in bilaterians. Proc Natl Acad Sci U S A (2013) 110(22):E2028-37. doi: 10.1073/ pnas. 1219956110

3. Nässel DR, Winther AM. Drosophila neuropeptides in regulation of physiology and behavior. Prog Neurobiol (2010) 92(1):42-104.doi: 10.1016/j.pneurobio.2010.04.010

4. Dockray GJ. Cholecystokinin and gut-brain signalling. Regul Pept (2009) 155(13):6-10. doi: 10.1016/j.regpep.2009.03.015

5. Downer KE, Haselton AT, Nachman RJ, Stoffolano JG Jr. Insect satiety: sulfakinin localization and the effect of drosulfakinin on protein and carbohydrate ingestion in the blow fly, Phormia regina (Diptera: Calliphoridae). J Insect Physiol (2007) 53(1):106-12. doi: 10.1016/j.jinsphys.2006.10.013

6. Janssen T, Meelkop E, Lindemans M, Verstraelen K, Husson SJ, Temmerman L, et al. Discovery of a cholecystokinin-gastrin-like signaling system in nematodes. Endocrinology (2008) 149(6):2826-39. doi: 10.1210/en.2007-1772

7. Moran TH. Cholecystokinin and satiety: current perspectives. Nutrition (2000) 16(10):858-65. doi: 10.1016/S0899-9007(00)00419-6

8. Söderberg JA, Carlsson MA, Nässel DR. Insulin-producing cells in the Drosophila brain also express satiety-inducing cholecystokinin-like peptide, drosulfakinin. Front Endocrinol (2012) 3:109. doi: 10.3389/fendo.2012.00109
9. Nachman RJ, Holman GM, Haddon WF, Ling N. Leucosulfakinin, a sulfated insect neuropeptide with homology to gastrin and cholecystokinin. Science (1986) 234(4772):71-3. doi: 10.1126/science.3749893

10. Hauser F, Cazzamali G, Williamson M, Blenau W, Grimmelikhuijzen CJ. A review of neurohormone GPCRs present in the fruitfly Drosophila melanogaster and the honey bee Apis mellifera. Prog Neurobiol (2006) 80(1):1-19. doi: 10.1016/j. pneurobio.2006.07.005

11. Kubiak TM, Larsen MJ, Burton KJ, Bannow CA, Martin RA, Zantello MR, et al Cloning and functional expression of the first Drosophila melanogaster sulfakinin receptor DSK-R1. Biochem Biophys Res Commun (2002) 291(2):313-20. doi: 10.1006/bbrc.2002.6459

12. Nichols R, Schneuwly SA, Dixon JE. Identification and characterization of a Drosophila homologue to the vertebrate neuropeptide cholecystokinin. J Biol Chem (1988) 263(25):12167-70.

13. Yu N, Smagghe G. CCK(-like) and receptors: structure and phylogeny in a comparative perspective. Gen Comp Endocrinol (2014):doi: 10.1016/j. ygcen.2014.05.003

14. Mönnikes H, Lauer G, Arnold R. Peripheral administration of cholecystokinin activates c-fos expression in the locus coeruleus/subcoeruleus nucleus, dorsal vagal complex and paraventricular nucleus via capsaicin-sensitive vagal afferents and CCK-A receptors in the rat. Brain Res (1997) 770(1-2):277-88. doi: 10.1016/ S0006-8993(97)00865-2

15. Williams MJ, Goergen P, Rajendran J, Zheleznyakova G, Hagglund MG, Perland E, et al. Obesity-linked homologues TfAP-2 and Twz establish meal frequency in Drosophila melanogaster. PLoS Genet (2014) 10(9):e1004499. doi: 10.1371/journal. pgen.1004499

16. Jensen RT. Involvement of cholecystokinin/gastrin-related peptides and their receptors in clinical gastrointestinal disorders. Pharmacol Toxicol (2002) 91(6):333-50. doi: 10.1034/j.1600-0773.2002.910611.x

17. Rehfeld JF, Friis-Hansen L, Goetze JP, Hansen TV. The biology of cholecystokinin and gastrin peptides. Curr Top Med Chem (2007) 7(12):1154-65. doi: $10.2174 / 156802607780960483$

18. Nichols R. Signaling pathways and physiological functions of Drosophila melanogaster FMRFamide-related peptides. Annu Rev Entomol (2003) 48:485-503. doi: 10.1146/annurev.ento.48.091801.112525

19. Harshini S, Nachman RJ, Sreekumar S. In vitro release of digestive enzymes by FMRF amide related neuropeptides and analogues in the lepidopteran insect Opisina arenosella (Walk.). Peptides (2002) 23(10):1759-63. doi: 10.1016/ S0196-9781(02)00152-3

20. Nichols R, Lim IA. Spatial and temporal immunocytochemical analysis of drosulfakinin (Dsk) gene products in the Drosophila melanogaster central nervous system. Cell Tissue Res (1996) 283(1):107-16. doi: 10.1007/s004410050518

21. Veenstra JA, Agricola HJ, Sellami A. Regulatory peptides in fruit fly midgut. Cell Tissue Res (2008) 334(3):499-516. doi: 10.1007/s00441-008-0708-3

22. Park D, Veenstra JA, Park JH, Taghert PH. Mapping peptidergic cells in Drosophila: where DIMM fits in. PLoS One (2008) 3(3):e1896. doi: 10.1371/journal. pone. 0001896

23. Maestro JL, Aguilar R, Pascual N, Valero ML, Piulachs MD, Andreu D, et al. Screening of antifeedant activity in brain extracts led to the identification of sulfakinin as a satiety promoter in the German cockroach. Are arthropod sulfakinins homologous to vertebrate gastrins-cholecystokinins? Eur J Biochem (2001) 268(22):5824-30. doi: 10.1046/j.0014-2956.2001.02527.x

24. Meyering-Vos M, Muller A. RNA interference suggests sulfakinins as satiety effectors in the cricket Gryllus bimaculatus. J Insect Physiol (2007) 53(8):840-8. doi: 10.1016/j.jinsphys.2007.04.003

25. Wei Z, Baggerman G, Nachman J, Goldsworthy G, Verhaert P, De Loof A, et al. Sulfakinins reduce food intake in the desert locust, Schistocerca gregaria. J Insect Physiol (2000) 46(9):1259-65. doi: 10.1016/S0022-1910(00)00046-9

26. Wicher D, Derst C, Gautier H, Lapied B, Heinemann SH, Agricola HJ. The satiety signaling neuropeptide perisulfakinin inhibits the activity of central neurons promoting general activity. Front Cell Neurosci (2007) 1:3. doi: 10.3389/ neuro.03.003.2007

27. Bader R, Colomb J, Pankratz B, Schrock A, Stocker RF, Pankratz MJ. Genetic dissection of neural circuit anatomy underlying feeding behavior in Drosophila: distinct classes of hugin-expressing neurons. J Comp Neurol (2007) 502(5):848-56. doi: $10.1002 / \mathrm{cne} .21342$

28. Bader R, Sarraf-Zadeh L, Peters M, Moderau N, Stocker H, Kohler K, et al. The IGFBP7 homolog Imp-L2 promotes insulin signaling in distinct neurons 
of the Drosophila brain. J Cell Sci (2013) 126(Pt 12):2571-6. doi: 10.1242/ jcs. 120261

29. Pool AH, Scott K. Feeding regulation in Drosophila. Curr Opin Neurobiol (2014) 29C:57-63. doi: 10.1016/j.conb.2014.05.008

30. Bellier B, Crete D, Million ME, Beslot F, Bado A, Garbay C, et al. New CCK2 agonists confirming the heterogeneity of CCK2 receptors: characterisation of BBL454. Naunyn Schmiedebergs Arch Pharmacol (2004) 370(5):404-13. doi: 10.1007/ s00210-004-0969-7

31. Li Q, Deng X, Singh P. Significant increase in the aggressive behavior of transgenic mice overexpressing peripheral progastrin peptides: associated changes in CCK2 and serotonin receptors in the CNS. Neuropsychopharmacology (2007) 32(8):1813-21. doi: 10.1038/sj.npp.1301304

32. Zwanzger P, Domschke K, Bradwejn J. Neuronal network of panic disorder: the role of the neuropeptide cholecystokinin. Depress Anxiety (2012) 29(9):762-74. doi: 10.1002/da.21919

33. Raud S, Innos J, Abramov U, Reimets A, Koks S, Soosaar A, et al. Targeted invalidation of CCK2 receptor gene induces anxiolytic-like action in light-dark exploration, but not in fear conditioning test. Psychopharmacology (Berl) (2005) 181(2):347-57. doi: 10.1007/s00213-005-2255-X

34. Alekseyenko OV, Lee C, Kravitz EA. Targeted manipulation of serotonergic neurotransmission affects the escalation of aggression in adult male Drosophila melanogaster. PLoS One (2010) 5(5):e10806. doi: 10.1371/journal.pone.0010806

35. Certel SJ, Leung A, Lin CY, Perez P, Chiang AS, Kravitz EA. Octopamine neuromodulatory effects on a social behavior decision-making network in Drosophila males. PLoS One (2010) 5(10):e13248. doi: 10.1371/journal. pone. 0013248

36. Williams MJ, Goergen P, Rajendran J, Klockars A, Kasagiannis A, Fredriksson R, et al. Regulation of aggression by obesity-linked genes TfAP-2 and Twz through octopamine signaling in Drosophila. Genetics (2014) 196(1):349-62. doi: 10.1534/ genetics.113.158402

37. Zhou C, Rao Y. A subset of octopaminergic neurons are important for Drosophila aggression. Nat Neurosci (2008) 11(9):1059-67. doi: 10.1038/nn.2164
38. Chen X, Peterson J, Nachman RJ, Ganetzky B. Drosulfakinin activates CCKLR-17D1 and promotes larval locomotion and escape response in Drosophila. Fly (2012) 6(4):290-7. doi: 10.4161/fly.21534

39. Chen X, Ganetzky B. A neuropeptide signaling pathway regulates synaptic growth in Drosophila. J Cell Biol (2012) 196(4):529-43. doi: 10.1083/jcb.201109044

40. Koon AC, Ashley J, Barria R, DasGupta S, Brain R, Waddell S, et al. Autoregulatory and paracrine control of synaptic and behavioral plasticity by octopaminergic signaling. Nat Neurosci (2011) 14(2):190-9. doi: 10.1038/nn.2716

41. Koon AC, Budnik V. Inhibitory control of synaptic and behavioral plasticity by octopaminergic signaling. J Neurosci (2012) 32(18):6312-22. doi: 10.1523/ JNEUROSCI.6517-11.2012

42. Luo J, Lushchak OV, Goergen P, Williams MJ, Nässel DR. Drosophila insulin-producing cells are differentially modulated by serotonin and octopamine receptors and affect social behavior. PLoS One (2014) 9(6):e99732. doi: 10.1371/journal. pone.0099732

Conflict of Interest Statement: The authors declare that the research was conducted in the absence of any commercial or financial relationships that could be construed as a potential conflict of interest.

Received: 31 October 2014; accepted: 01 December 2014; published online: 18 December 2014.

Citation: Nässel DR and Williams MJ (2014) Cholecystokinin-like peptide (DSK) in Drosophila, not only for satiety signaling. Front. Endocrinol. 5:219. doi:10.3389/ fendo.2014.00219

This article was submitted to the journal Frontiers in Endocrinology.

Copyright $\odot 2014$ Nässel and Williams. This is an open-access article distributed under the terms of the Creative Commons Attribution License (CC BY). The use, distribution or reproduction in other forums is permitted, provided the original author(s) or licensor are credited and that the original publication in this journal is cited, in accordance with accepted academic practice. No use, distribution or reproduction is permitted which does not comply with these terms. 